\title{
Editorial
}

\section{¿Entran el axonema y las mitocondrias espermáticas en el oocito durante el proceso de la fecundación?}

\section{Do the spermatic anoxeme and mitochondria enter the oocyte during the fertilization process?}

La fecundación es el proceso por el cual un espermatozoide y un oocito interactúan, y para que este proceso se lleve a cabo el espermatozoide necesita sufrir una serie de cambios fisiológicos y bioquímicos por su paso a través del tracto reproductivo femenino, los cuales le permiten capacitarse y sufrir la reacción acrosomal al entrar en contacto con la zona pelúcida. Posteriormente, se iniciará la singamina, el desarrollo embrionario temprano, la implantación y el desarrollo embrionario tardío, que dará origen a un nuevo individuo ${ }^{1,2}$.

Este interesante evento de interacción intergametos genera dos preguntas que son bastantes importantes, y que fueron motivo de discusión en la Línea de Trabajo Académica - Grupo Reproducción, Semillero de investigación SIMBIOSIS, Escuela de Microbiología, Universidad de Antioquía: a) ¿entra todo el espermatozoide en el oocito, incluyendo el axonema y las mitocondrias? y b) si entra, ¿qué pasa con las mitocondrias espermáticas después de la fecundación?

Reconocidos investigadores en el mundo han tratado de entender cuál es el papel adicional del espermatozoide en la fecundación, aparte de proveer su material genético ${ }^{3-6}$. Durante el proceso de fecundación en seres humanos el espermatozoide contribuye en al menos 3 puntos claves:

1. Entregar el material genético haploide.

2. Generar la señal de iniciación de la activación del oocito.

3. Proporcionar el centriolo7.

El objetivo de este editorial es tratar de resolver las dos preguntas anteriormente planteadas, basadas en el conocimiento actual.

En los mamíferos tanto el axonema como las mitocondrias entran en el oocito durante la fecundación ${ }^{5}$, y no existe duda alguna después de observar la fotografía del grupo de Sathananthan et $\mathrm{al}^{8}$ (citado y reproducido en Ankel-Simons et $\mathrm{al}^{3}$ ) donde se observa claramente esta interacción en seres humanos. Hasta donde se conoce actualmente, los únicos ejemplos descritos que no cumplen esta regla son el hámster chino (Cricetulus griseus) y la lombriz (Nereis) en los cuales el axonema no entra en el oocito $3,9,10$.

Las mitocondrias espermáticas en embriones de algunos mamíferos como ratas, bovinos y ratones ${ }^{11}$, son destruidas antes o durante el tercer clivaje embrionario por una maquinaria proteolítica en el citoplasma oocitario. Esto ha sido evidenciado mediante la detección de las mitocondrias durante el proceso de espermiogénesis, usando un anticuerpo específico que reconoce la ubiquitina; estas mitocondrias posteriormente son degradadas por el proteasoma 26S en el citoplasma del oocito fecundado ${ }^{12}$. Adicionalmente, la incapacidad del oocito para eliminar las mitocondrias que son aportadas por el espermatozoide supone una causa de alteración en el desarrollo embrionario en animales clonados mediante transferencia nuclear ${ }^{13}$. Una interesante justificación para la eliminación de las mitocondrias espermáticas es que estas son dañadas por las especies reactivas de oxígeno durante la espermatogénesis, o a través del viaje del espermatozoide hacia el oocito y, por lo tanto, podrían ser deletéreas para el embrión ${ }^{14,15}$. Por otro lado existe la posibilidad de una dilución de las mitocondrias paternas, ya que un espermatozoide lleva alrededor de 100 copias de ADN mitoncondrial; en contraste, el oocito contiene entre $10^{5}$ y $10^{8}$ copias $^{16}$, por lo tanto la contribución paterna de ADN mitocondrial podría ser diluida hasta tal punto que fuera imposible detectar las mitocondrias paternas usando los análisis convencionales ${ }^{17}$.

Un procedimiento bastante común en nuestros tiempos para solucionar problemas de fertilidad es la inyección intracitoplasmática de espermatozoides (ICSI) ${ }^{18}$, que consiste en la introducción directa de un espermatozoide completo (cabeza, pieza intermedia y cola) en un oocito. Torroni et $\mathrm{al}^{19}$ reportan que después de analizar el halogrupo del ADN mitocondrial en los padres y su descendencia, en tres familias cuyos hijos fueron obtenidos por ICSI (dos con un hijo y la otra con tres hijos) todos ellos poseen sólo mitocondrias maternas. En 2004, en un estudio realizado por Johnson et $\mathrm{al}^{20}$ se demostró que el ICSI realizado con espermatozoides completos tiene 
más éxito que el realizado sólo con las cabezas espermáticas, seguramente debido a la necesidad del axonema, o al menos del centrosoma, que es importante durante el desarrollo del embrión ${ }^{21}$, y se ha observado que realizar procesos de fecundación con espermatozoides completos parece contribuir al normal desarrollo de la embriogénesis ${ }^{22}$.

Por su parte, Terada et $\mathrm{al}^{23}$ demostraron que cuando el espermatozoide es incorporado dentro del citoplasma de un oocito el centrosoma espermático es responsable del arreglo periférico de microtúbulos, lo cual es esencial para el movimiento pronuclear, que origina la unión del genoma paterno y materno. Además, los centrosomas espermáticos se replican durante el primer ciclo y forman los dos polos del huso mitótico requeridos para el desarrollo embrionario ${ }^{23}$.

En conclusión, las mitocondrias y el axonema entran en el oocito, pero son degradados poco después de iniciado el proceso de fecundación, y aunque en la actualidad aún es debatido y poco conocido el papel de cada una de estas organelas en el proceso reproductivo, basándonos en la evidencia existente, seguramente tanto el axonema como las mitocondrias podrían estar implicadas en el desarrollo embrionario.

\section{B I B L I O G R A F Í A}

1. Cardona Maya WD, Cadavid AP. La reacción acrosomal: cinco décadas después de su descubrimiento. Ginecol Obstet Mex. 2006;74(5):282-3.

2. Cardona Maya WD, Cadavid Jaramillo AP. Complementariedad intergametos, breve revisión. Arch Esp Urol. 2004;57(10): 1107-12.

3. Ankel-Simons F, Cummins JM. Misconceptions about mitochondria and mammalian fertilization: implications for theories on human evolution. Proc Natl Acad Sci USA. 1996;93(24):13859-63.

4. Sutovsky P. Ubiquitin-dependent proteolysis in mammalian spermatogenesis, fertilization, and sperm quality control: killing three birds with one stone. Microsc Res Tech. 2003;61(1):88-102.

5. Yanagimachi R. Male gamete contributions to the embryo. Ann N Y Acad Sci. 2005;1061:203-7.

6. Gil Villa AM, Cardona-Maya WD, Cadavid Jaramillo AP. Muerte embrionaria temprana: ¿tiene influencia el factor masculino? Arch Esp Urol. 2007;60(9):1057-68.

7. Barroso G, Valdespin C, Vega E, Kershenovich R, Ávila R, Avendano C, et al. Developmental sperm contributions: fertilization and beyond. Fertil Steril. 2009;92(3):835-48.

8. Sathananthan AH, Naj SC, Edirisingh R, Ratham SS, Wong PC. Human sperm-egg interaction in vitro. Gamete Res. 1986;15:317-26.

9. Pickworth S, Change MC. Fertilization of Chinese hamster eggs in vitro. J Reprod Fertil. 1969;19(2):371-4.

10. Fechter J, Schoneberg A, Schatten G. Excision and disassembly of sperm tail microtubules during sea urchin fertilization: requirements for microtubule dynamics. Cell Motil Cytoskeleton. 1996;35(4):281-8.

11. Sutovsky P, Moreno RD, Ramalho-Santos J, Dominko T, Simerly C, Schatten G. Ubiquitinated sperm mitochondria, selective proteolysis, and the regulation of mitochondrial inheritance in mammalian embryos. Biol Reprod. 2000;63(2):582-90.

12. Sutovsky P, Moreno RD, Ramalho-Santos J, Dominko T, Simerly C, Schatten G. Ubiquitin tag for sperm mitochondria. Nature. 1999;402(6760):371-2.

13. St John JC, Lloyd RE, Bowles EJ, Thomas EC, El Shourbagy S. The consequences of nuclear transfer for mammalian foetal development and offspring survival. A mitochondrial DNA perspective. Reproduction. 2004;127(6):631-41.

14. Cummins J. Mitochondrial DNA in mammalian reproduction. Rev Reprod. 1998;3(3):172-82.

15. Cummins JM, Jequier AM, Kan R. Molecular biology of human male infertility: links with aging, mitochondrial genetics, and oxidative stress? Mol Reprod Dev. 1994;37(3):345-62.

16. Birky CW Jr. The inheritance of genes in mitochondria and chloroplasts: laws, mechanisms, and models. Annu Rev Genet. 2001;35:125-48.

17. Gyllensten U, Wharton D, Josefsson A, Wilson AC. Paternal inheritance of mitochondrial DNA in mice. Nature. 1991;352(6332):255-7.

18. Palermo G, Joris H, Devroey P, Van Steirteghem AC. Pregnancies after intracytoplasmic injection of single spermatozoon into an oocyte. Lancet. 1992;340(8810):17-8.

19. Torroni A, D'Urbano L, Rengo C, Scozzari R, Sbracia M, Manna $C$, et al. Intracytoplasmic injection of spermatozoa does not appear to alter the mode of mitochondrial DNA inheritance. Hum Reprod. 1998;13(6):1747-9.

20. Johnson JE, Higdon HL 3rd, Blackhurst DW, Boone WR. Expectations for oocyte fertilization and embryo cleavage after whole sperm versus sperm head intracytoplasmic sperm injection. Fertil Steril. 2004;82(5):1412-7.

21. Palermo GD, Bedford JM. Viability of sperm without tails? Fertil Steril. 2005;83(4):1067.

22. Moomjy M, Colombero LT, Veeck LL, Rosenwaks Z, Palermo GD. Sperm integrity is critical for normal mitotic division and early embryonic development. Mol Hum Reprod. 1999;5(9):836-44.

23. Terada Y, Nakamura SI, Hewitson L, Simerly C, Horiuchi $\mathrm{T}$, Murakami T, et al. Human sperm aster formation after intracytoplasmic sperm injection with rabbit and bovine eggs. Fertil Steril. 2002;77(6):1283-4.

W. Cardona Maya* y Á. P. Cadavid

Grupo Reproducción, Sede de investigación Universitaria, Universidad de Antioquia, Medellín, Colombia

*Autor para correspondencia.

Correo electrónico: wdcmaya@medicina.udea.edu.co (W. Cardona Maya) 